\title{
Commentary: Mitral valve repair wins again
}

\author{
Marc Gillinov, MD, Daniel J. P. Burns, MD, MPhil, \\ and Per Wierup, MD, $\mathrm{PhD}$
}

What patient would not prefer to end the day with his or her own mitral valve rather than a porcine, bovine, or mechanical valve? Hundreds of articles extoll the benefits of mitral valve repair over mitral valve replacement. In fact, valve replacement in the mitral valve recipient is often categorized as a failure, even when the patient survives the operation, has no complications, and returns to full activity a few weeks after hospital discharge. If that patient arrives home with a prosthetic valve (rather than a valve repair), questions abound.

The aforementioned comments refer to patients with degenerative mitral valve disease. Although there are no randomized trials comparing repair with replacement in such patients, we believe that repair is unquestionably preferable to replacement in those with mitral valve prolapse..$^{1-3}$ But what about rheumatic mitral valve disease? In that context, the repair versus replacement literature is relatively sparse, and conclusions less certain. Fu and colleagues ${ }^{4}$ seek to address this knowledge gap.

Rheumatic mitral valve disease is far more prevalent in China than in the United States or Western Europe. With a relatively large number of cases, the authors were able to develop expertise in repair of the rheumatic valve. In a series of 1644 patients with rheumatic mitral valve disease, these expert surgeons achieved valve repair in $612(37 \%)$. Compared with those undergoing replacement, patients receiving repair were more likely to have predominant mitral regurgitation, a larger valve orifice area, commissural calcification, and subvalvular thickening. Overall, a

\footnotetext{
From the Department of Thoracic and Cardiovascular Surgery, Cleveland Clinic, Cleveland, Ohio.

Disclosures: M.G. has relationships with Edwards Lifesciences, Medtronic, Abbott, CryoLife, Johnson and Johnson, AtriCure, and ClearFlow. D.J.P.B. has relationships with Medtronic and CryoLife. P.W. has relationships with Medtronic, Edwards Lifesciences, and CryoLife.

Received for publication Jan 29, 2020; accepted for publication Feb 1, 2020; available ahead of print Feb 7, 2020.

Address for reprints: Marc Gillinov, MD, Department of Thoracic and Cardiovascular Surgery, Cleveland Clinic/Desk J4-1, 9500 Euclid Ave, Cleveland, OH 44195 (E-mail: gillinom@ccf.org).

J Thorac Cardiovasc Surg 2021;162:83

$0022-5223 / \$ 36.00$

Copyright (c) 2020 by The American Association for Thoracic Surgery

https://doi.org/10.1016/j.jtcvs.2020.02.001
}



CENTRAL MESSAGE

Mitral valve repair is superior to replacement in patients with rheumatic mitral valve disease.

minority of patients had anatomic features that made them suitable for repair. Therefore, we can conclude that the majority of patients with rheumatic mitral valve disease are most suitable for valve replacement.

Still, repair should always be considered. Using propensity matching to compare repair and replacement, the authors found that, as with degenerative disease, repair conferred clinical advantages. Specifically, those undergoing valve repair had superior early and midterm survival and greater freedom from valve-related events with only a modest increase in the risk of reoperation in the first few years after surgery.

From this work, we can conclude that mitral valve repair is preferable to replacement in rheumatic patients when feasible. By using these authors' criteria for repair, the majority of patients will receive a valve replacement. Therefore, rheumatic disease is fundamentally different from degenerative disease. In the rheumatic patient, the surgeon should consider repair but should not mourn if replacement is necessary.

\section{References}

1. David TE, David CM, Tsang W, Lafreniere-Roula M, Manlhiot C. Long-term results of mitral valve repair for regurgitation due to leaflet prolapse. J Am Coll Cardiol. 2019;74:1044-53.

2. Gillinov AM, Blackstone EH, Nowicki ER, Slisatkorn W, Al-Dossari G, Johnston DR, et al. Valve repair versus valve replacement for degenerative mitral valve disease. J Thorac Cardiovasc Surg. 2008;135:885-93. 893.e1-2.

3. Suri RM, Schaff HV, Dearani JA, Sundt TM, Daly RC, Mullany CJ, et al. Survival advantage and improved durability of mitral repair for leaflet prolapse subsets in the current era. Ann Thorac Surg. 2006;82:819-26.

4. Fu J, Li Y, Zhang H, Han J, Du J, Meng X. Outcomes of mitral valve repair compared with replacement for patients with rheumatic disease. J Thorac Cardiovasc Surg. 2021;161:72-82.e7. 